\title{
DESCENDING NECROTIZING MEDIASTINITIS: CERVICOTOMY OR THORACOTOMY?
}

\author{
Alessandro Brunelli, MD, Armando Sabbatini, MD, Giovanbattista Catalini, MD, and Aroldo Fianchini, MD, \\ Ancona, Italy
}

In a former issue of the Journal, Marty-Ane and colleagues ${ }^{1}$ emphasized the importance of thoracotomy in descending necrotizing mediastinitis (DNM). They considered cervicotomy alone insufficient for adequate mediastinal drainage.

Recently, we had a case of DNM at our institution. This condition was successfully treated through a transcervical approach. A 49-year-old man with carious teeth was admitted with a painful swollen neck (anterolateral on the right side), trismus, and high fever. Examination revealed brawny edema and tenderness of the right side of the neck, extending downward to the right shoulder and right arm. Subcutaneous emphysema was present. A chest roentgenogram showed gas in the soft tissue of the neck and a widened mediastinum, along with bilateral pleural effusion. A cervicothoracic computed tomographic scan that was immediately obtained revealed soft-tissue infiltration with gas bubbles in the right side of the neck, with involvement of the right supraclavicular region and fascial planes of the right arm. Fluid and air were seen in the anterior part of the mediastinum, along with bilateral pleural effusion; this was suggestive of mediastinitis.

The patient was promptly taken to the operating room, where he underwent a right third mandibular molar odontectomy and transcervical drainage of the right and left compartments of the neck, as well as of the anterior mediastinum, through a bilateral and anterior cervjcotomy. Incisions over the right clavicle and along the medial side of the right arm were also performed to drain these regions. After extensive drainage and débridement, wounds were kept packed open to facilitate drainage of pus and frequent irrigation. Cultures revealed Staphylococcus aureus, and immediate intravenous therapy with imipenem (500 $\mathrm{mg}$ every 4 hours) and vancomycin ( $2 \mathrm{gm}$ ) was started on the basis of sensitivity studies. On postoperative day 3 , a chest roentgenogram showed a worsening of the left pleural effusion, necessitating a chest-tube thoracostomy. After the first surgical drainage, the patient was taken to the operating room another six times for secondary exploration, débridement, and partial suture of the wounds. His condition slowly improved and his temperature became normal, the chest tube was re-

From the Department of Thoracic Surgery, University of Ancona, School of Medicine, Ancona, Italy.

Accepted for publication May 1, 1995.

J Thorac Cardiovasc Surg 1996;111:485-6

Copyright (C) 1996 by Mosby-Year Book, Inc.

$0022-5223 / 96 \$ 5.00+0 \quad \mathbf{1 2 / 5 4 / 6 6 2 2 2}$ moved, and the patient was discharged on postoperative day 30 without physical or roentgenographic signs of mediastinitis.

Mediastinitis occasionally occurs as a consequence of oropharyngeal infection. Because of its rapid spread along cervical fascial planes-as well as through them-and its almost always delayed diagnosis, DNM is regarded as the most lethal form of mediastinitis. ${ }^{2}$ Even in the antibiotic era, mortality rates are as high as $40 \% .^{3}$ Marty-Ane and associates ${ }^{1}$ reported a survival of $83 \%$ among six patients treated at their institution for DNM. They recommended transthoracotomy mediastinal drainage without attempting transcervical drainage alone, regardless of the level of involvement into the mediastinum.

Our case demonstrated that transcervical drainage, if performed without delay, may be successful in treating patients with DNM, even complicated by pleural effusion and necrotizing fascitis of the right arm, as long as the infection is limited to the superior mediastinum above the carina, as advocated by Estrera and associates. ${ }^{3}$ Because the level of involvement of the mediastinum depends on the interval between the onset of the primary cervical infection and the recognition of the mediastinitis, we think that the outcome of DNM is strictly dependent on the delay of diagnosis. If the process is promptly recognized, we believe that thoracotomy may not be necessary. We strongly advocate the early use of cervicothoracic computed tomographic scan in every case of laterocervical infection, because plain chest roentgenograms may be not diagnostic until the process has diffusely spread into the mediastinum.

In the era before computed tomographic scanning, we treated at our institution a patient with DNM caused by perforation of the hypopharynx for difficult endotracheal intubation. Before the diagnosis of DNM was made the patient, a 24-year-old man, underwent cervicotomy for drainage of the cervical infection, bilateral tube thoracostomy for drainage of pleural effusion, and subxiphoid drainage for treatment of cardiac tamponade. Chest roentgenograms did not show any sign of mediastinal involvement until 8 days after the onset of the primary infection, when the process had spread well into the mediastinum. Cervicomediastinal drainage through a lateral and anterior cervicotomy proved insufficient, and a right thoracotomy was necessary. Foul-smelling, purulent material was drained from well below the fourth thoracic vertebra posteriorly, indicative of a critical delay in the diagnosis. After thoracotomy, the patient's condition improved, and he was discharged on postoperative day 28 without sequelae. Although Marty-Ane and colleagues ${ }^{1}$ reported an unfavorable outcome in the only patient who 
did not undergo thoracotomy, it would be interesting to know the delay between onset of primary infection and diagnosis for each patient in their series. They reported a range of 6 to 20 days.

In conclusion, we consider the systematic use of thoracotomy in DNM, as suggested by Marty-Ane and associates, ${ }^{1}$ inappropriate. We support the less aggressive conclusions of Estrera and colleagues, ${ }^{3}$ who recommend transthoracotomy approach only if the mediastinitis has spread below the tracheal bifurcation anteriorly or the fourth thoracic vertebra posteriorly.

\section{REFERENCES}

1. Marty-Ane CH, Alauzen M, Alric P, Serres-Cousine O, Mary $\mathrm{H}$. Descending necrotizing mediastinitis advantage of mediastinal drainage with thoracotomy. J THORaC Cardiovasc Surg 1994;107:55-61.

2. Pearse HE. Mediastinitis following cervical suppuration. Ann Surg 1938;108:588-611.

3. Estrera AS, Landay MJ, Grisham JM, et al. Descending necrotizing mediastinitis. Surg Gynecol Obstet $1983 ; 157: 545-52$.

\title{
MYASTHENIA GRAVIS, PSYCHIATRIC DISTURBANCES, IDIOPATHIC THROMBOCYTOPENIC PURPURA, AND LICHEN PLANUS ASSOCIATED WITH CERVICAL THYMOMA
}

\author{
Tommaso Claudio Mineo, MD, Fausto Biancari, MD, and Vito D'Andrea, MD, Rome, Italy
}

Jaretzki and Wolff ${ }^{1}$ in 1988 recommended the maximal thymectomy procedure in the treatment of myasthenia gravis with or without thymoma and of thymoma with or without myasthenia gravis. The wide mediastinal and cervical exposure ensures complete removal of all thymic tissue and eventually of ectopic thymus. Recently, this operation allowed us to find a small cervical thymoma and to perform a curative resection in a patient with multiple autoimmune disorders.

The patient was a 32-year-old woman who successfully underwent splenectomy, followed by administration of immune serum globulin, in 1988 for the treatment of idiopathic thrombocytopenic purpura unresponsive to corticosteroids. In December 1994, the patient was admitted to our hospital with petechiae, mucous membrane bleeding, bilateral ptosis, and nasal speech. She also had oral lichen planus. Results of laboratory examinations were remarkable for a platelet count of $11,000 \mathrm{cells} / \mathrm{ml}$. A direct Dixon test had positive results for the presence of antiplatelet autoantibodies. A bone marrow biopsy specimen showed an increased number of megakaryocytes and hypoproduction of platelets. No signs of myelodisplastic syndrome were observed, and a normal karyotype was revealed by chromosomal analysis. Her serum antibody against acetylcholine receptor was high $(19.4 \mathrm{pmol} / \mathrm{ml})$, and electromyography confirmed the diagnosis of myasthenia gravis. Chest radiography and computed tomography failed to reveal any intrathoracic and extrathoracic abnormalities. Treatment was started, but the patient's condition responded poorly to pyridostigmine bromide (60 mg orally every 6 hours) and prednisone (50 $\mathrm{mg} /$ day).

From the Department of Thoracic Surgery, University of Tor Vergata, Rome, Italy.

Accepted for publication August 9, 1995.

J Thorac CARdiovasc Surg 1996;111:486-7

Copyright (C) 1996 by Mosby-Year Book, Inc

$0022-5223 / 96 \$ 5.00+0 \quad \mathbf{1 2 / 5 4 / 6 8 5 5 5}$
When seen by us in February 1995, the patient had petechiae, severe shortness of breath, ptosis, myopathic facies, nasal speech, dysarthria, dysphagia of both liquids and solids with nasal regurgitation, and generalized weakness. The patient reported recent memory loss and had gustatory and olfactory hallucinations. She also became dysphoric. Pulmonary function tests revealed forced vital capacity of $2.2 \mathrm{~L}$ ( $90 \%$ predicted), and forced expiratory volume in 1 second of $1.7 \mathrm{~L}$ (42\% predicted). Arterial blood gases with the patient breathing room air revealed an arterial oxygen tension of $68 \mathrm{~mm} \mathrm{Hg}$, an arterial carbon dioxide tension of $29 \mathrm{~mm} \mathrm{Hg}$, and a $\mathrm{pH}$ of 7.50 . Plasmaphereses were performed in five sessions, and $4500 \mathrm{ml}$ of plasma was exchanged. After this treatment, the patient's respiratory status, myasthenic symptoms, and psychiatric symptoms improved, and pyridostigmine bromide was successfully readministered ( $60 \mathrm{mg}$ orally every 8 hours).

Two units of platelets concentrate were transfused prophylactically, and the patient underwent a total median sternotomy with extensive removal of all thymic tissue, mediastinal fat, and both mediastinal pleural sheets. The dissection was continued through a transverse low cervical incision and a $1 \times 3 \mathrm{~cm}$ flat, well-encapsulated, solid mass was found under the sternocleidomastoid muscle, connected to the left superior pole of the thymus gland and adherent to the left lobe of the thyroid. The mass, which was easily and completely excised, was histologically classified as an epithelial, medullary type, Masaoka stage I thymoma. Microscopic examination of the removed mediastinal tissue demonstrated involution of normal thymic tissue without any specific findings. The patient made an uneventful recovery and was discharged 11 days after the operation on a regimen of prednisone $(50 \mathrm{mg} /$ day) and pyridostigmine $(60 \mathrm{mg}$ orally every 8 hours). Two months later, platelet count had increased to 210,000 cells $/ \mathrm{ml}$ and results of direct Dixon test were negative. At the same time, oral lesions completely disappeared and she was able to stop taking steroids. Four 